\title{
29 \\ The IT Artifact and Telecommuting
}

\author{
France Bélanger ${ }^{1}$, Mary Beth Watson-Manheim ${ }^{2}$, Susan Harrington ${ }^{3}$, \\ Nancy Johnson ${ }^{4}$, and Derrick Neufeld ${ }^{5}$ \\ 1 Virginia Tech, belanger@vt.edu \\ 2 University of Illinois at Chicago, mbwm@uic.edu \\ 3 Macon State College, sharrington@mail.maconstate.edu \\ 4 Metropolitan State University, nancy.jo.johnson@att.net \\ 5 University of Western Ontario, dneufeld@ivey.uwo.ca,
}

\begin{abstract}
Research on the concept of telecommuting or telework, as it is known in various areas of the world, has appeared in information systems (IS) and non-IS publications for more than 20 years. Research areas with respect to telecommuting are quite varied, from Information and Communication Technologies (ICT) use, to transportation, managerial control, work-life issues, and more. A significant number of these studies have taken into account the role of technology in enabling telecommuting. However, recent awareness of the IT artifact issue [1] has raised concerns for some authors, reviewers, and editors as to when the technology component is significant enough to consider some of the telecommuting research as IS research. Others, meanwhile, believe that by definition telecommuting addresses the IT artifact issue, and that this should not be a concern. In this panel, we explore the question of whether the IT artifact is an issue in IS-related telecommuting research by examining topics from multiple and sometimes competing perspectives.
\end{abstract}

\section{Panel Description}

Research on the concept of telecommuting has appeared in information systems (IS) and non-IS publications for more than 20 years. A significant number of studies have taken into account the role of technology in enabling telecommuting. However, recent awareness of the IT artifact issue [1] has raised concerns for some authors, reviewers, and editors as to when the technology component is significant enough to consider some of the telecommuting research as IS research. Others, meanwhile, believe that by definition telecommuting addresses the IT artifact issue, and that this 
should not be a concern. The panel is composed of well renowned academics who have extensively conducted and published research on telecommuting. The panel discussion will focus on the question of whether the IT artifact is an issue in ISrelated telecommuting research by examining topics from multiple and sometimes competing perspectives. Individual panelists will present different perspectives, and hear feedback on these positions from the other panelists and the audience. Below are some of the discussions to be presented by the panel.

Question 1. Is telecommuting research part of the IS body of research when it does not explicitly study the IT artifact but rather focuses on non-ICT issues such as "transportation, managerial control, work-life issues" etc?

In 2003, Benbasat and Zmud [2] argued that for an article to be considered IS research it must address the immediate nomological net of the "IT artifact" (the interaction among information technology applications, structures, and contexts). This essentially normative position, rooted in the Aristotelian laws of formal, didactic logic, presumes that the identity of our field is in danger, and that we need to safeguard our identity by erecting a set of definitive boundaries to establish what is in, and what is out. In sharp contrast, an alternative descriptive conception of the identity of our field has been voiced by other thought leaders, for example, King and Lyytinen [3],. The descriptive perspective, based in an epistemology of dialectical logic, contends that IS research is comprised of whatever IS researchers do, and that the identity of the field is pragmatically and inclusively defined by the sum total of whatever the body of IS scholars chooses to investigate, however focused or diversified. To answer the question presented above, Benbasat and Zmud [2] would say no. Their argument would lead to the conclusion that these aspects of telecommuting are not in the immediate nomological net and are best left to researchers familiar with organizational management, organizational culture, and psychology. Moreover, use of IT to support telecommuting is not an IT per se but a conglomeration of technologies that are used to facilitate remote work. So immediately one would say that telecommuting fails the test of an IT artifact in the strict approach of Benbasat and Zmud. Alternatively, the contrasting approach of King and Lyytinen [3] would suggest that telecommuting research, even when focusing on secondary "non-ICT" issues, is part of the body of IS research.

\section{Question 2. Is there enough discussion of IT in IS telecommuting research?}

IS-related telecommuting research often focuses on the management, organizational culture, and behavioral sides of telecommuting implementation. Depending on the definition of IT artifact and the nomological net that is appropriate for IS research, there may or may not be enough discussion of IT in telecommuting research. However, if an IT is perceived as an information processing tool or a social relations tool [1], then telecommuting meets the criteria. Orlikowski and Iacono [1] look at IT broadly and describe telecommuting as an artifact in need of new theories to make sense of the techno-social processes surrounding it, "because IT artifacts are designed, constructed, and used by people, they are shaped by the interests, values, and assumptions of a wide variety of communities of developers, investors, users, 
etc." (p. 131). Moreover, IT artifacts are usually made up of many often fragile and fragmentary components, are rarely flawless and unfailing, and are not static but are instead dynamic and changing. Without looking at the broader context and changing techno-social processes, we cannot understand the IT artifact.

\section{Question 3. Is the definition of telecommuting as an IT-enabled concept sufficient for addressing IT artifact concerns?}

Again this point is debatable and it could easily be argued that the telecommuting body of research has stretched too far into the context and non-IT subject areas that are not IT issues per se. Rarely do telecommuting researchers look at the precise implementation details or how those are managed from an operational perspective. Questions of what precise technologies (e-mail, chat, video connections, etc.) are used, how are they implemented and managed, and how the technologies are related to the purposes of telework are not usually the focus of telecommuting research nor collected as data. From that perspective, we have probably failed to focus on the IT artifact to the fullest extent possible - leaving a potential contribution to the IS field wanting. As a case in point, for years we have been wondering why telecommuting has not "taken off" as predicted yet, it may be that the ICTs available have not met the needs of the work to be performed. Now it appears that more and more telework is occurring in the form of outsourcing, not only to countries like India but in the form of "homesourcing" to housewives at home in Utah [4]. Have we missed a potential contribution to our field by focusing on non-IT issues when, had we analyzed the evolution of ICT technologies, we may have either predicted or designed new technologies that would facilitate telecommuting implementation?

\section{Question 4. There are important issues that should be more likely to occur} to IS researchers than those in other fields, e.g., security. Understanding behaviors and context can inform security procedures, but is this an IT artifact?

It could be argued that if we truly look at the tools or conglomeration of technologies in detail, we may have to include security, performance, ease of use, compatibility with existing systems, and most certainly their implementation. So the question we ask is what are the attributes of the IT and are these attributes part of the IT artifact? If security is an attribute of an IT, as it arguably is, then security is most certainly worthy of study. However, many of the attributes of an IT are perceptions, and perceptions of users and management influence the adoption and implementation of ICTs. Telecommuting is a prime example and so much of the research has focused on perceptions of trust, proper management, etc. Perceptions and context therefore are closely tied to the attributes of the IT. In the case of security, management's perception of security risks may thwart a telecommuting implementation. So it would appear that since security is an attribute of a telecommuting implementation, security concerns inform behaviors and context, and leads to the argument that yes, the context is part of the IT artifact. From an attribute perspective, we can argue that certain issues such as security and understanding the context and behaviors surrounding telecommuting implementation are part of the IT artifact. Moreover, the use of ICT by telecommuters is integral to the work environment but also reflexively 
influences how telecommuting is carried out, and how the work environment is structured. The IT artifact notion places bounds on what is to be studied and may unintentionally limit the contribution of the IS field in areas where it has significant expertise. In the case of security, uses of ICT can lead to innovative ways of working and managing that may have information security implications but are indirectly related to ICT. For example, recent research has found that remote team members are not always aware of the bounds of the total team membership [5]. While this finding may not be considered an issue related to the IT artifact, it clearly has information security implications (are members sure of the identity of the person they are giving information to?). Humans add an element of dynamism that increases the security concerns and make security issues dynamic. Because of the flow of information and the potential threat to that flow that evolving security issues pose, security is a part of the IT artifact. This type of argument shows that humans' use of the IT is an essential part of the IT artifact. But are behaviors made possible by the use of IT, and are their consequences still considered a part of the IT artifact?

\section{Panel Members}

Panel Facilitator: Mary Beth Watson-Manheim

Panelists: France Bélanger, Susan Harrington, Nancy Johnson, and Derrick Neufeld

\section{References}

1. W. Orlikowski and C.S. Iacono, Research Commentary: Desperately Seeking the "IT" in IT Research - A Call to Theorizing the IT Artifact, Information Systems Research 12(2), 121-134 (2001).

2. I. Benbasat and R.W. Zmud, The Identity Crisis Within the IS Discipline: Defining And Communicating the Discipline's Core Properties, MIS Quarterly 27(2), 183-194 (2003).

3. J. King and K. Lyytinen, Reach and grasp, MIS Quarterly 28(4), 539-551 (2004).

4. T. Friedman, The World Is Flat [Updated and Expanded]: A Brief History of the Twentyfirst Century (Farrar, Straus and Giroux, New York, 2006).

5. Mortensen and P. Hinds, Fuzzy Teams: Boundary Disagreement in Distributed and Collocated Teams, in: Distributed Work, edited by P. J. Hinds and S. Kiesler (MIT Press, Cambridge, Mass., 2002), pp. 283-308.

\section{About the Panelists}

Dr. Mary Beth Watson-Manheim is Associate Professor of IS in the Information Decision Sciences Department at the University of Illinois at Chicago. Dr. Watson-Manheim's research interests include impact of information and communication technologies on work; managerial, social, and technological implications of virtual work environments; and ITenabled organizational change. Her research has been published in such journals as MIS 
Quarterly, Journal of Management Information Systems, IEEE Journal of Professional Communications, Information Systems Journal, Group Decision and Negotiation, Information Technology and People, and others. Her research has been funded by Intel Corporation, IBM Center for the Business of Government, and Lotus Development Corporation.

Dr. France Bélanger is Associate Professor and Alumni Research Fellow of Information Systems at Virginia Tech. She is Associate Editor of MIS Quarterly and the Journal of Electronic Commerce in Organizations. Dr. Bélanger's research focuses on the use of telecommunication technologies in organizations, in particular for distributed work and electronic commerce. She is widely published in IS journals such as Information Systems Research, MIS Quarterly, Communications of the ACM, IEEE Transactions on Professional Communication, Information Systems Journal, and many others. She has co-authored two books. Her work has been funded by the National Science Foundation, Department of Education, and several corporations and research centers. She held a Fulbright Distinguished Chair in MIS in 2006.

Dr. Susan J. Harrington is professor and interim chair of the Information Technology Division at Macon State College. She was a professor of IS at Georgia College \& State University from 1994-2005 and at Kent State University-Stark campus from 1986-1994. She has 13 years of IS experience in industry. Her research interests include ethical decision making in organizations, IT adoption and diffusion, telecommuting/telework, information requirements analysis, trust, and corporate culture. She has studied the behavioral and managerial aspects of telework. She has published in MIS Quarterly, e-Service Journal, IEEE Transactions on Professional Communication, Journal of Business Ethics, DATABASE, Information \& Organisation, and several management journals.

Dr. Nancy Johnson has worked in academia for over twenty years, and in industry for twenty years. She is an adjunct faculty at Metropolitan State University, St. Mary's University, the Fielding Institute, and Potchefstroom University (South Africa). She was a faculty, Director of residential colloquia, and Associate Dean of Business at the School of Technology of Capella University. She was faculty at Metropolitan State University from 1991-2000. Author of five book chapters and numerous articles, she was guest editor for an issue on telecommuting of Journal of End User Computing and editor of a book on virtual offices. She was a Fulbright Scholar in 1992 in Malaysia. Her interests include human factors in successful change management, distance education, justification methodologies of IT investment in the public sector, and international use of IT.

Dr. Derrick Neufeld is Associate Professor of IS at the Richard Ivey School of Business. Dr. Neufeld's research is focused on the ways in which virtual organization impacts individuals, teams and managers. He is currently studying the effects and effectiveness of such topics as telecommuting (working at a distance), e-mail (communicating at a distance), group support systems (team-working at a distance) and remote leadership (managing others at a distance). His research has been published in Leadership Quarterly, Information \& Management, DATA BASE, Journal of Engineering and Technology Management, and Journal of Computer Information Systems. 